\title{
PESQUISAS COM INFÂNCIA E MÍDIAS: DESAFIOS ATUAIS E INSPIRAÇÕES
}

\author{
CHILDHOOD AND MEDIA RESEARCHES: \\ CURRENT CHALLENGES AND INSPIRATIONS
}

\section{Apresentação}

Este número temático reúne pesquisas que articulam as crianças como sujeitos na relação com as mídias, apontando alguns desafios que se apresentam nesse contexto particularmente crucial para a educação, bem como possíveis inspirações para novas pesquisas e práticas, sempre em construção. O papel cada vez maior das mídias no cotidiano infantil, especialmente a partir da intensificação da presença dos smartphones, videogames e demais dispositivos eletrônicos móveis, impõe questões difíceis e delicadas para se pensar hoje a escola, o cotidiano e a sensibilidade das crianças. Torna-se ainda mais aguçada a necessidade de se investigarem a fundo as relações da infância com a imagem, considerando o poder simbólico das indústrias midiáticas e dos interesses comerciais que veem as crianças mais como consumidoras do que como cidadãs.

Na perspectiva da pesquisa em educação, em que esta proposta se situa, os direitos das crianças à proteção, à provisão e à participação em sua relação com as mídias são balizas importantes, reconhecidos pela Convenção dos Direitos das Crianças (CDC) desde 1989 (UNICEF, 2019). A dificuldade na implementação das políticas que regulamentam as mídias no sentido da garantia desses direitos sobrecarrega ainda mais a escola e os educadores diante de uma pauta que deveria dizer respeito a toda a sociedade. Alguns dos temas emergentes no debate público e também nesse campo de estudos são: a necessidade de abordagens atualizadas de leitura e formação crítica para as mídias, que sejam adequadas aos novos tempos, tecnologias e discursos; a valorização da autoria e da agência infantis na cultura digital; as mediações na escola e na família ao uso de dispositivos móveis pelas crianças; a colonização do imaginário infantil pelo mercado; o corpo e o movimento das crianças no contexto dos multiletramentos; os atravessamentos entre consumo, infância e gênero; e as imagens das crianças no discurso midiático: o que se mostra e o que se esconde.

A pesquisa voltada à relação entre crianças e comunicação é um campo pulsante, dadas a novidade e a rapidez com que os fenômenos se sucedem, e considerando também as características singulares da infância. Por isso, é um território em que a invenção metodológica se faz especialmente necessária. Assim, a presente proposta procura também contemplar questões teórico-metodológicas de pesquisa, como a especificidade das metodologias qualitativas e quantitativas com crianças, com destaque para suas dimensões éticas, além do potencial da ludicidade e das linguagens artísticas na pesquisa com crianças.

A proposta teve sua origem na reunião do grupo temático Infância e Mídias, no $5^{\circ}$ Colóquio de Pesquisas em Educação e Mídias, realizado na Unirio em dezembro de 2016. Os pesquisadores doutores ali reunidos eram líderes de grupos de pesquisa do Nordeste, do Centro, do Sudeste e do Sul do país - grupos esses com longo histórico e compromisso de estudo consistente no campo. Naquela ocasião, foi enfatizada, de modo consensual, a 
especificidade das pesquisas sobre a relação entre infância e mídias, tanto no contexto mais amplo da relação entre educação e mídias quanto no dos Estudos da Infância. Foi ressaltada ainda a necessidade de uma articulação maior entre os pesquisadores dessa interface no Brasil, incluindo a dimensão interdisciplinar, tão importante para o estudo da relação entre crianças e mídias, expressa ali na presença de pesquisadores tanto do campo da Educação quanto da Comunicação, parceria que se mantém nesta proposta.

Todos os líderes dos grupos de pesquisa presentes naquele encontro atenderam ao convite para participar deste número temático, o que garante sua representatividade em termos de qualificação acadêmica e de diversidade regional. A organicidade da proposta foi também facilitada pelo compromisso assumido pelos pesquisadores ali reunidos, com a continuidade do debate articulado sobre os desafios temáticos e teóricos no campo. Os artigos que integram a coletânea, como se poderá perceber a seguir, buscam ser exemplo do diálogo em rede que temos buscado construir.

Em “Por uma ética nas produções audiovisuais na cibercultura: a infância em vídeos virais", os autores Rita Marisa Ribes Pereira e Perseu Silva, do grupo de pesquisa Infância e Cultura Contemporânea (UERJ), discutem a responsabilidade dos adultos que gravam e publicam vídeos de crianças em cenas cotidianas, muitas vezes em situações que as expõem de forma problemática. A partir de uma perspectiva ética, eles fazem uma crítica contundente à objetificação da imagem das crianças nas práticas sensacionalistas de vídeos que acabam viralizando nas redes.

No artigo “'Cuidado com quem você fala na Internet': mediação parental pelo olhar de préadolescentes", Teresa Sofia Castro, professora da Universidade Nova de Lisboa, aborda, sob a ótica de crianças entre 10 e 12 anos, a influência da mídia nas percepções dos pais sobre o consumo digital, associadas à noção de risco e à disseminação de pânico, e suas estratégias para lidar com as mediações parentais mais intrusivas. Em seus depoimentos, os pré-adolescentes reconhecem como justa a preocupação dos pais com suas práticas on-line, mas afirmam também seus direitos digitais à privacidade e à participação.

Em "Infâncias, cultura visual e consumo: reflexões de pesquisas", a autora Adriana Hoffmann, do grupo de pesquisa Comunicação, Audiovisual, Cultura e Educação (CACE/Unirio), faz uma retrospectiva de pesquisas sobre a relação das crianças com as imagens, a partir dos trabalhos realizados ao longo de vinte anos de experiência em pesquisa. Desse percurso, emergem evidências da centralidade cada vez maior do visual na experiência cultural infantil, assim como os dilemas que tal contexto traz para a escola e a formação das crianças.

O artigo "Olhar cuidadoso: uma pesquisa visual com crianças" foi escrito por Wendy Luttrell, professora do Programa de Doutorado em Educação Urbana da City University of New York (CUNY). Ela reflete sobre uma pesquisa etnográfica que, ao longo de onze anos, acompanhou crianças de uma periferia urbana, enquanto elas produziam fotografias sobre seu cotidiano. Tal pesquisa investigou as representações das crianças sobre raça, etnicidade, gênero e classe, bem como sobre sua condição de imigrantes. $O$ trabalho destaca a potência das fotografias tiradas pelas crianças para compor contranarrativas que questionam as representações dominantes impostas a elas.

Em “Crianças e mídias: três polêmicas e desafios contemporâneos”, os autores Gilka Girardello, Monica Fantin e Rogério Santos Pereira, do Núcleo Infância, Comunicação, Cultura e Arte (UFSC), colocam em foco três temas polêmicos nas atuais discussões sobre a vida das crianças na cultura digital, considerando também o agravamento do cenário causado pela crise sanitária de 2020. Para apresentar o contexto dessas polêmicas, os autores trazem manifestos, reportagens e publicações atuais de vários países a respeito das necessidades de mediação adulta na relação das crianças com as telas, dos modos de lidar com a desinformação no contexto mundial de fake news e do lugar do corpo na relação das crianças com o digital.

No artigo "Infância e mídias digitais: histórias de crianças e adolescentes sobre seus cotidianos", de autoria de Geusiane Miranda de Oliveira Tocantins e Ingrid Dittrich Wiggers, do Imagem - Grupo de 
Pesquisas sobre Corpo e Educação (UnB), as narrativas gráficas de crianças e adolescentes sobre suas relações com as tecnologias são o mote a partir do qual as pesquisadoras abordam os processos de apropriação dos dispositivos midiáticos, marcados pelo uso individualizado e diverso, mas similares quanto à extensão crescente que vêm alcançando em tempos e espaços do cotidiano.

O texto "Um baú mágico: histórias e aventuras para crianças surdas numa web TV", escrito por Maria Inês Batista Barbosa e Luiz Augusto Coimbra de Rezende Filho, do Núcleo de Tecnologia Educacional (UFRJ), apresenta o processo de produção do programa Baú do Tito, na TV INES (Instituto Nacional de Educação de Surdos), pensando um produto midiático com total acessibilidade para crianças e adultos surdos. $\mathrm{O}$ artigo reflete sobre o processo de construção do programa, ao ser protagonizado por crianças usando a língua de sinais, para o debate das temáticas da área das Ciências Naturais, trazendo o modo como pensa a criança e os desafios na construção do roteiro e dos estudos entre ouvintes e não ouvintes.

Por fim, em "Crianças YouTubers e o exercício do direito à comunicação", as autoras Inês S. Vitorino Sampaio, Georgia C. Pereira e Andrea P. P. Cavalcante, do Laboratório de Pesquisa da Relação Infância, Juventude e Mídia (UFC), avaliam a playlist do YouTube Rico vs Pobre, procedendo a uma análise do discurso de cinco vídeos. O texto problematiza o lugar de fala e de expressão da criança no YouTube, sob a ótica dos seus direitos digitais, consubstanciados no direito à proteção, à provisão e à participação, apontando o modo como as desigualdades sociais aparecem nos vídeos em questão.

Assim, como se pode verificar pelo leque de temáticas e referências teórico-metodológicas expresso nos artigos, esperamos que esta publicação contribua para enfrentar um dos desafios que nos animam como pesquisadores das relações entre mídias e infâncias no Brasil: o de aproximar os universos de professores, pesquisadores e crianças, tanto no âmbito das empirias quanto no das linguagens.

\section{Referência}

UNICEF. Convenção sobre os Direitos da Criança. Disponível em: https://www.unicef.org/brazil/convencao-sobre-os-direitos-da-crianca. Acesso em: 18 set. 2019.

1.Universidade Federal de Santa Catarina - Florianópolis (SC), Brasil.

2.Universidade Federal do Estado do Rio de Janeiro - Rio de Janeiro (RJ), Brasil.

3.Universidade Federal do Ceará - Fortaleza (CE), Brasil.

*Autora correspondente: gilkagirardello@gmail.com

Editoras Associadas: Adriana Laplane e Lucia Reily 